\title{
Cortactin promotes cell migration and invasion through upregulation of the dedicator of cytokinesis 1 expression in human colorectal cancer
}

\author{
XIAOQIAN JING ${ }^{*}$, HUO WU* ${ }^{*}$ XIAOPIN JI, HAOXUAN WU, MINMIN SHI and REN ZHAO \\ Department of Surgery, Ruijin Hospital, Shanghai Jiao Tong University School of Medicine, Shanghai 200025, P.R. China
}

Received April 20, 2016; Accepted August 16, 2016

DOI: $10.3892 /$ or.2016.5058

\begin{abstract}
Cortactin (CTTN), a major substrate of the Src tyrosine kinase, has been implicated in cell proliferation, motility and invasion in various types of cancer. However, the molecular mechanisms of CTTN-driven malignant behavior remain unclear. In the current study, we determined the expression of CTTN in colorectal cancer and investigated its underlying mechanism in the metastasis of colorectal cancer. We confirmed increased CTTN expression in lymph node-positive CRC specimens and highly invasive CRC cell lines. Further study has shown that overexpression of CTTN promoted CRC cell migration and invasion, whereas CTTN silencing inhibited CRC cell migratory and invasive capacities in vitro. Mechanistically, CTTN increases expression of dedicator of cytokinesis 1 (DOCK1) and gene silencing of DOCK1 partially abolishes the migration and invasion capacity by CTTN. Our findings indicate that CTTN promotes metastasis of CRC cells by increasing DOCK1 expression and this could offer a promising therapeutic target for colorectal cancer treatment.
\end{abstract}

\section{Introduction}

Colorectal cancer (CRC) is one of the most aggressive gastrointestinal malignancies and the third leading cause of cancer deaths in the world $(1,2)$. However, in recent years, its incidence has been increasing in economically transitioning countries due to physical inactivity and consumption of calorie-dense food $(3,4)$. Although surgical resection has been considered to be the effective treatment for early-stage patients, approximately $20-45 \%$ of patients who underwent

Correspondence to: Professor Ren Zhao, Department of Surgery, Ruijin Hospital Shanghai Jiao Tong University School of Medicine, Shanghai Institute of Digestive Surgery, No. 197 Ruijin Er Rd, Shanghai 200025, P.R. China

E-mail: rjzhaoren@139.com

${ }^{*}$ Contributed equally

Key words: colorectal cancer, CTTN, DOCK1, invasion, migration curative resection developed metastasis or relapse (5-7). Tumor metastasis is a multistep process in which cancer cells escape from the primary, penetrate hematogenously and colonize at distant sites (8-10). Thus, understanding the genetic basis and molecular mechanism of initiation and progression of CRC will help to find novel therapeutic targets for CRC patients.

Cortactin (CTTN), a v-Src substrate, was reported overexpressed in a variety of cancers including lung, breast, and prostate cancers (11). CTTN was increased in head and neck carcinogenesis and correlated with poor prognosis (12). CTTN promoted cell motility and tumor metastasis by binding and activating the actin-related protein $2 / 3$ complex to regulate the formation of invadopodia (13). In addition, overexpression of cortactin has been shown to enhance cell adhesion and form lamellipodium, which contributed to the lamellipodial persistence and migration phenotypes (14). Conversely, CTTN silencing inhibited cell motility in woundhealing, cell migration and Matrigel invasion assays (15). CTTN has been reported upregulated in colorectal cancer tissues and overexpression of CTTN promoted cell migration and invasion by interacting with zonula occludens-1 (ZO-1) (16). However, the clinical significance and the underlying molecular mechanism of CTTN in the progression of $\mathrm{CRC}$ remained to be determined.

In this study, we investigated CTTN expression in CRC tissue and its relationship with the clinicopathological factors and prognosis of the CRC patients. Furthermore, we explored the potential role of CTTN in CRC cell mobility and the underlying molecular mechanisms in vitro.

\section{Materials and methods}

Tissues specimens. A total of 146 paired formalin-fixed paraffin-embedded CRC and adjacent normal tissue specimens were obtained from stage I-III CRC patients who received curative surgery in Ruijin hospital from May 2009 to July 2010. These patients were diagnosed by pathological analysis. According to the tumor-node-metastasis (TNM) staging system of the American Joint Committee on Cancer (AJCC, 7 th edition), 63 cases (43.2\%) were in disease stage I/II and 83 cases $(56.8 \%)$ were in disease stage III. Written informed consent was obtained from all patients. This study was approved by the Committee of Medical Ethics at Shanghai Jiao Tong University. 
Immunohistochemistry. Immunohistochemistry of paraffinembedded tissue sections was performed as previously described (17). In brief, tissue sections from paraffin blocks were deparaffinised and rehydrated. Endogenous peroxidase activity was blocked with $3 \% \mathrm{H}_{2} \mathrm{O}_{2}$ for $10 \mathrm{~min}$. Antigen retrieval was performed in citrate buffer $(10 \mathrm{mM}, \mathrm{pH} 6.0)$ for $15 \mathrm{~min}$ at $100^{\circ} \mathrm{C}$. The sections were incubated with a primary antibody (Anti-CTTN antibody, Sigma-Aldrich, HPA057242) at $4^{\circ} \mathrm{C}$ overnight in a moist chamber. Finally, the visualization signal was developed with diaminobenzidine (Dako). Images of these slides stained for CTTN were scanned at x20 magnification and captured by microscopy (DP70, Olympus, Tokyo, Japan). The final staining scores were evaluated by two pathologists without prior knowledge of the clinical data.

Cell culture. Human colorectal cancer cell lines (SW480 and SW620) were obtained from Shanghai Cell Bank of the Chinese Academy of Sciences (Shanghai, China) and maintained in RPMI-1640 (Hyclone, Logan, UT, USA) supplemented with $10 \%$ fetal bovine serum (Invitrogen, Grand Island, NY, USA), penicillin $(100 \mathrm{U} / \mathrm{ml})$, and streptomycin $(100 \mathrm{mg} / \mathrm{ml})$ at $37^{\circ} \mathrm{C}$ in a humidified atmosphere of $5 \% \mathrm{CO}_{2}$.

Establishment of CTTN-knockdown and CTTN-overexpressing cells. The plasmid and lentivirus particles for CTTN overexpression or knockdown were designed and constructed by Shanghai GenePharma Co., Ltd. (Shanghai, China). SW480 cells were transduced with Lenti-GFP (vector) or Lenti-CTTN (CTTN) at $20 \mathrm{MOI}$ in the presence of the $8 \mu \mathrm{g} / \mathrm{ml}$ polybrene (Sigma). SW620 cells were transduced with Lenti-control (control) or Lenti-shCTTN (shCTTN) at $20 \mathrm{MOI}$ in the presence of the $8 \mu \mathrm{g} / \mathrm{ml}$ polybrene. Cells were selected stable cell lines continuously in puromycin $(2 \mu \mathrm{g} / \mathrm{ml})$.

siRNA transfection. CTTN-overexpressing SW480 cells were transfected with negative control (NC) or DOCK1 siRNA using Lipofectamine RNA interference MAX Reagent (Life Technologies) according to the manufacturer's instructions. The siRNAs targeting CTTN and negative control were obtained from Shanghai GenePharma Co., Ltd.

Cell adhesion assay. Approximately $2 \times 10^{5}$ cells were harvested and resuspended in complete medium and then seeded into a 24-well plate that was precoated with matrix proteins (20 $\mu \mathrm{g} / \mathrm{ml}$ fibronectin or $20 \mu \mathrm{g} / \mathrm{ml}$ laminin). After incubating for $1 \mathrm{~h}$, cells were washed twice with PBS to remove the nonadherent cells. The bound cells were determined by WST-1 (Roche, Mannheim, Germany) at a wavelength of $450 \mathrm{~nm}$ in a microplate reader. The change in optical density was represented as fold of control.

Migration and invasion assay. Transwell migration assays were performed in 24-well plates with $8 \mu \mathrm{m}$ pore polycarbonate membrane (Corning, Tewksbury, MA, USA). Cells $\left(5 \times 10^{5}\right)$ were starved for $12 \mathrm{~h}$ and then added into the upper chambers of the wells in $100 \mu \mathrm{l}$ serum-free medium. RPMI-1640 medium $(600 \mu \mathrm{l})$ with $10 \%$ fetal bovine serum was added into the lower chamber. Cells were incubated for $36 \mathrm{~h}$ at $37^{\circ} \mathrm{C}$ to allow cell invasion into the lower chamber. The invaded cells were fixed and stained with $0.5 \%$ crystal violet. Images were
Table I. Associations between CTTN expression and multiple clinicopathological factors in CRC patients.

\begin{tabular}{|c|c|c|c|}
\hline \multirow[b]{2}{*}{ Variables } & \multicolumn{2}{|c|}{$\begin{array}{c}\text { CTTN expression } \\
\text { level }\end{array}$} & \multirow[b]{2}{*}{$\mathrm{P}$-value } \\
\hline & $\begin{array}{l}\text { Low } \\
\mathrm{N}=73\end{array}$ & $\begin{array}{l}\text { High } \\
\mathrm{N}=73\end{array}$ & \\
\hline \multicolumn{4}{|l|}{ Gender } \\
\hline Female & 25 & 27 & NS \\
\hline Male & 48 & 46 & \\
\hline \multicolumn{4}{|l|}{ Age, years } \\
\hline$\leq 60$ & 40 & 31 & NS \\
\hline$>60$ & 33 & 42 & \\
\hline \multicolumn{4}{|l|}{ Tumor size, $\mathrm{cm}$} \\
\hline$\leq 5$ & 38 & 42 & NS \\
\hline$>5$ & 35 & 31 & \\
\hline \multicolumn{4}{|c|}{ Tumor differentiation } \\
\hline Well & 19 & 21 & NS \\
\hline Moderate & 44 & 36 & \\
\hline Poor & 10 & 16 & \\
\hline \multicolumn{4}{|c|}{ Preoperative CEA (ng/ml) } \\
\hline$\leq 5$ & 49 & 44 & NS \\
\hline$>5$ & 24 & 29 & \\
\hline \multicolumn{4}{|l|}{ Depth of invasion } \\
\hline Muscular layer & 40 & 27 & 0.031 \\
\hline Serosa layer & 33 & 46 & \\
\hline \multicolumn{4}{|c|}{ Lymph node metastasis } \\
\hline No & 48 & 27 & 0.0005 \\
\hline Yes & 25 & 46 & \\
\hline \multicolumn{4}{|l|}{ TNM stage } \\
\hline I-II stage & 39 & 24 & 0.012 \\
\hline III stage & 34 & 49 & \\
\hline
\end{tabular}

Fisher's exact tests or $\chi^{2}$ tests for all the other analysis.

taken by microscopy (Olympus) at least in 8 representative fields. Invasion assay was performed with filters pre-coated with Matrigel (BD Biosciences, Franklin Lakes, NJ, USA) and the following protocols were the same as migration assay.

Western blot analysis. Cells were lysed with RIPA buffer (Cell Signaling Technology, Danvers, MA, USA), and the protein concentration was measured using the BCA assay (Thermo Fisher Scientific, Waltham, MA, USA). Equal amounts of protein were subjected to $10 \%$ SDS-PAGE for electrophoresis and transferred to a polyvinylidene difluoride membrane (Millipore, Billerica, MA, USA). The membrane was blocked with $5 \%$ fat-free milk at room temperate, then specific antibody anti-CTTN antibody (Sigma-Aldrich), anti-DOCK1 antibody (Abcam, Cambridge, MA, USA), anti-RAC1 antibody (Sigma-Aldrich), and anti-GAPDH antibody (Cell Signaling 

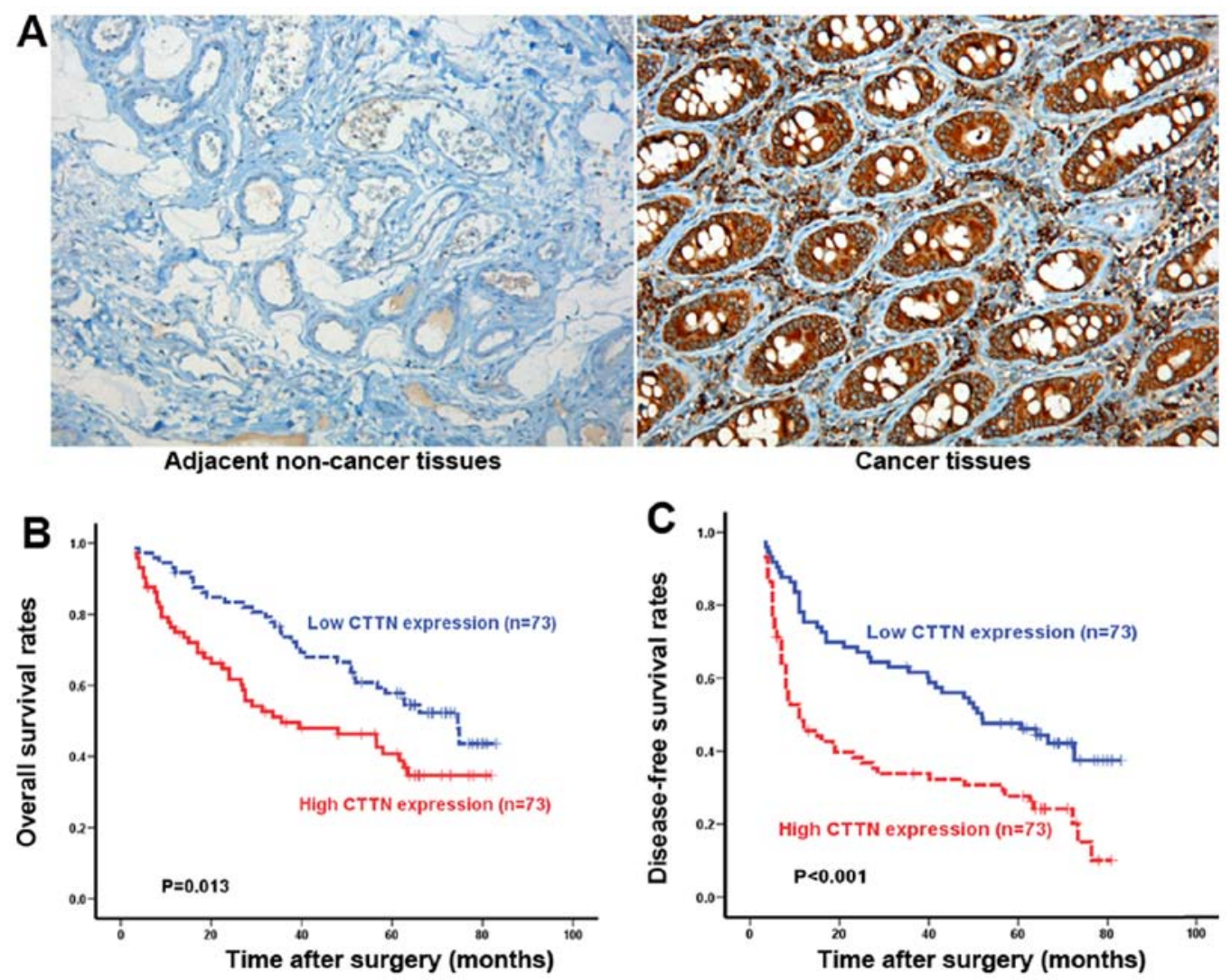

Figure 1. CTTN is upregulated in human CRC tissues and associated with poor prognosis. (A) Representative staining of CTTN in non-tumor colorectal tissues and primary CRC tissues. Kaplan-Meier analysis was performed to assess (B) overall survival and (C) disease-free survival in CRC patients according to the expression level of CTTN.

Technology) were incubated overnight at $4^{\circ} \mathrm{C}$. Immunoreactive bands were visualized with enhanced chemiluminescence (Thermo Fisher Scientific) using LAS 4000 imaging system (Fijifilm, Tokyo, Japan).

Statistical analysis. Data are presented as the mean \pm standard deviation of the mean. The $\chi^{2}$ test and the Fisher's test were used to test correlations between CTTN expression and clinicopathological parameters. Kaplan-Meier analysis with log-rank test was performed to assess patient survival. Data were analyzed using software SPSS 17.0 (SPSS Inc., Chicago, IL, USA) and a value of $\mathrm{P}<0.05$ was considered to indicate a statistically significant difference.

\section{Results}

CTTN is upregulated in colorectal cancer tissues. Previous studies have shown that CTTN was increased in many types of human cancers, including colorectal cancer (11). However, the expression of CTTN in Chinese colorectal cancer was unknown. IHC was used to detect the expression of CTTN in 146 paired CRC and adjacent normal tissues. In 94 cases (64\%), CTTN is expressed in the tumor tissues, mainly localized in the cell cytoplasm (Fig. 1A). In contrast, no or weak staining is seen in the cytoplasm of adjacent normal colorectal tissues (Fig. 1A). The relationship between CTTN expression and clinicopathological features is displayed in (Table I). We found CTTN expression was significantly correlated with depth of invasion $(\mathrm{P}<0.001)$, lymph node involvement
$(\mathrm{P}<0.001)$, distant metastasis $(\mathrm{P}<0.031)$, lymph node metastasis $(\mathrm{P}<0.005)$, and TNM stage $(\mathrm{P}=0.012)$. On the contrary, no significant differences between CTTN expression and gender, age, tumor size, tumor differentiation, or preoperative CEA level were observed. To further determine if the expression of CTTN was associated with colorectal cancer patient survival, Kaplan-Meier curve analysis is performed to assess prognosis. As shown in Fig. 1B, patients with high $(\mathrm{n}=73)$ CTTN expression had a significantly short overall survival (OS) than those with low $(\mathrm{n}=73)$ CTTN expression $(\mathrm{P}=0.013)$. There is also a statistically significant difference in disease-free survival (DFS) between patients whose tumors had high or low CTTN expression $(\mathrm{P}<0.001)$ (Fig. 1C). These data strongly indicated that CTTN expression play an important role in the progression of colorectal cancer.

Knockdown of CTTN inhibits cellular matrix adhesion, migration and invasion in vitro. Since CTTN is increased in colorectal cancer patients, we knocked down the CTTN expression in SW620 cells (high invasion capability) to investigate the biological behavior. Compared with the negative control (control) and blank, the levels of CTTN protein was significantly decreased in SW620 cells transfected with shCTTN (Fig. 2A). To investigate the effect of CTTN on the migration and invasion of SW620 cells, cell adhesion was first assessed and the results indicated knockdown of CTTN caused lower adhesion capability (Fig. 2B). Furthermore, Transwell analysis showed that knockdown of CTTN decreases the migration and invasion of SW620 cells compared to control (Fig. 2C). 

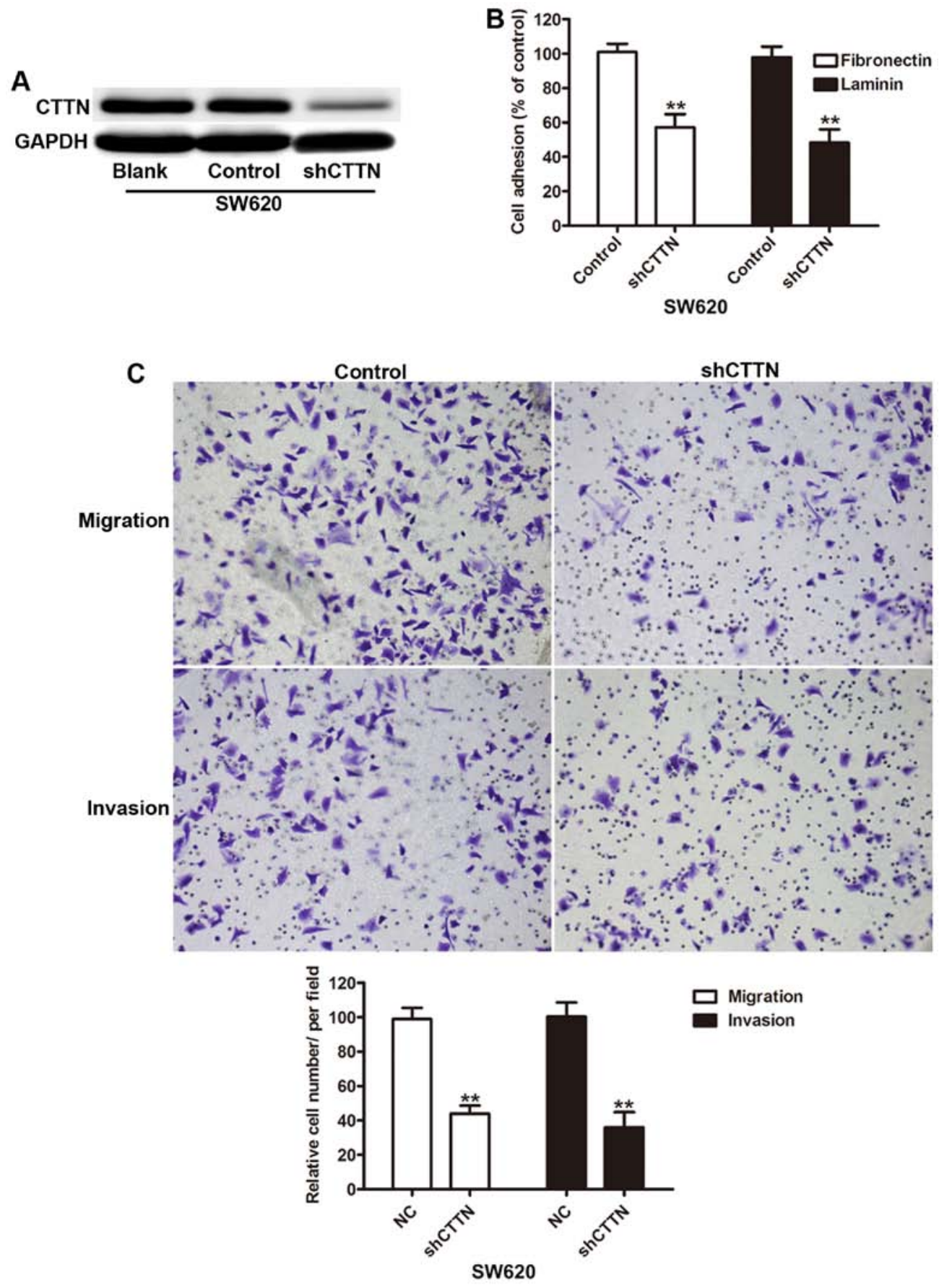

Figure 2. Effects of CTTN knockdown on cell invasion. (A) Western blot assays was used to determine knockdown efficiency. (B) Downregulation of CTTN could remarkably decrease the adhesion capability in SW620 cells. (C) Transwell invasion assay without or with Matrigel was employed to determine the effect of CTTN silencing on SW620 cell invasion. ${ }^{* *} \mathrm{P}<0.01$.

CTTN promotes cellular matrix adhesion, migration and invasion in vitro. Next we explored whether CTTN expression impacts the invasion capability, SW480 cells (low invasion capability) were transfected with CTTN. Western blot results showed CTTN expression was significantly increased in the CTTN group compared with the control vector and blank groups (Fig. 3A). Gain of function of CTTN enhanced the adhesion capability of SW480 cells transfected with CTTN (Fig. 3B). The cell invasion assay revealed a significant increase in the average number of cells penetrating the Transwell membrane and Matrigel in the CTTN group
(Fig. 3C). These findings suggested that CTTN played an important role in cell invasion.

CTTN mediates DOCK1 expression in colorectal cancer cells. To further determine the mechanisms that CTTN promote CRC cell invasion, we performed bioinformatic analysis to predict protein interactions. We focused on DOCK1, which has been documented as an oncogene in human cancers (Fig. 4A) $(18,19)$. As showed in Fig. 4B, DOCK1 was significantly increased in CTTN overexpressing cells as compared with control vector and consistently decreased DOCK1 

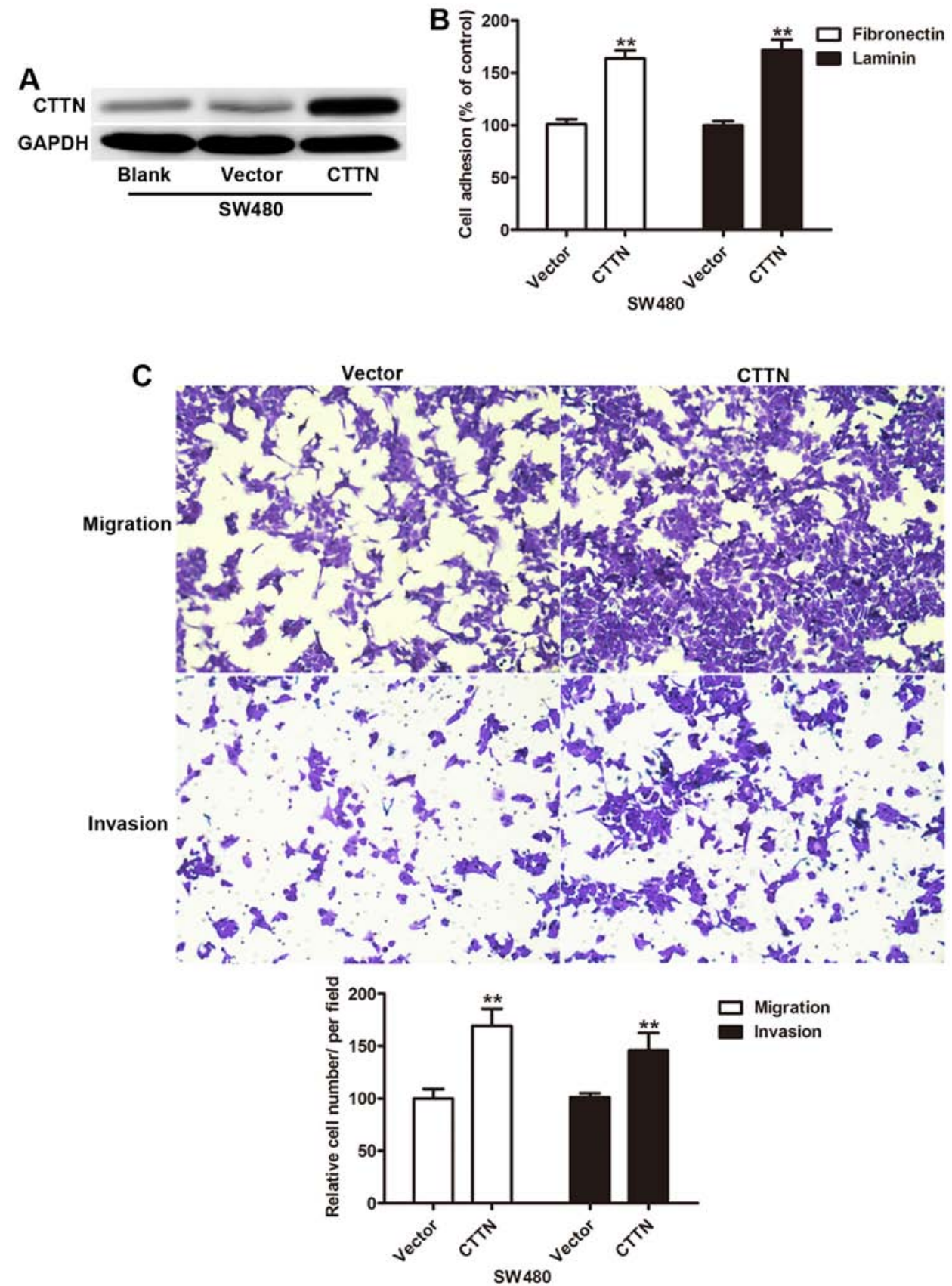

Figure 3. CTTN promotes cell migration and invasion. (A) Western blot analysis showed the expression level of CTTN protein was significantly upregulated in SW480 cells transfected with CTTN. (B) CTTN enhances the adhesion capability in SW480 cells. (C) SW480 cell migration and invasion were enhanced by CTTN overexpression. ${ }^{* * *} \mathrm{P}<0.01$.

expression in SW620 cells by knockdown of CTTN. In addition, we also observed Rac1, a downstream molecule, had a similar expression (Fig. 4B). These results indicated that the expression level of DOCK1 was upregulated by CTTN in CRC cell lines and prompted us to investigate the role of DOCK1 in CTTN-mediated cell invasion.

DOCK1 is required for CTTN-induced cell migration and invasion. To further investigate the role of DOCK1 in CTTN-mediated cell mobility, we knocked down DOCK1 in SW480 cells with stable overexpression of CTTN. As shown in Fig. 5A, compared to negative control (NC), transfection with the siRNA1, siRNA2, and siRNA3 results in inhibition of DOCK1 expression. siRNA2 had the most effective inhi- bition and was used in the remainder of the study. Then we measured the adhesion capability of SW480 cells and found DOCK1 silencing abrogated the effects of CTTN on adhesion capability (Fig. 5B). Furthermore, inhibition of DOCK1 also reduced the mean number of cells penetrating the Transwell membrane and Matrigel (Fig. 5C), suggesting that DOCK1 plays a crucial role in cell mobility of CRC cells and is involved in CTTN-mediated tumor metastasis.

\section{Discussion}

Growing evidence shows a direct link between disorder gene expression and cancer invasion and metastasis (20). Aberrant activation of cortactin (CTTN) has been implicated in 

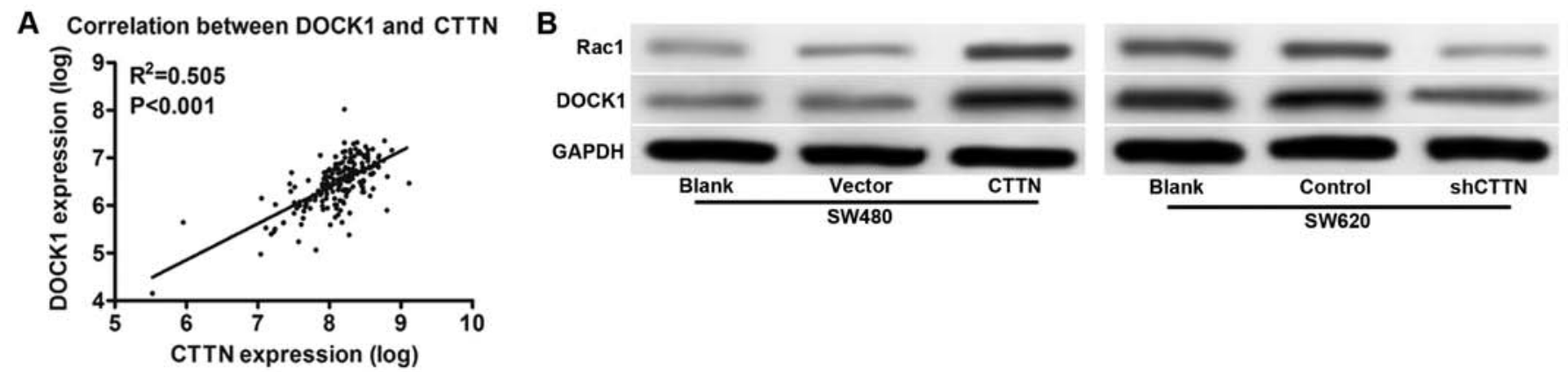

Figure 4. Effect of CTTN on the expression of DOCK1. (A) The correlation of CTTN and DOCK1 was predicted by bioinformatic analysis. (B) The expression of DOCK1 and Rac1 were determined by western blotting as indicated. ${ }^{* *} \mathrm{P}<0.01$.
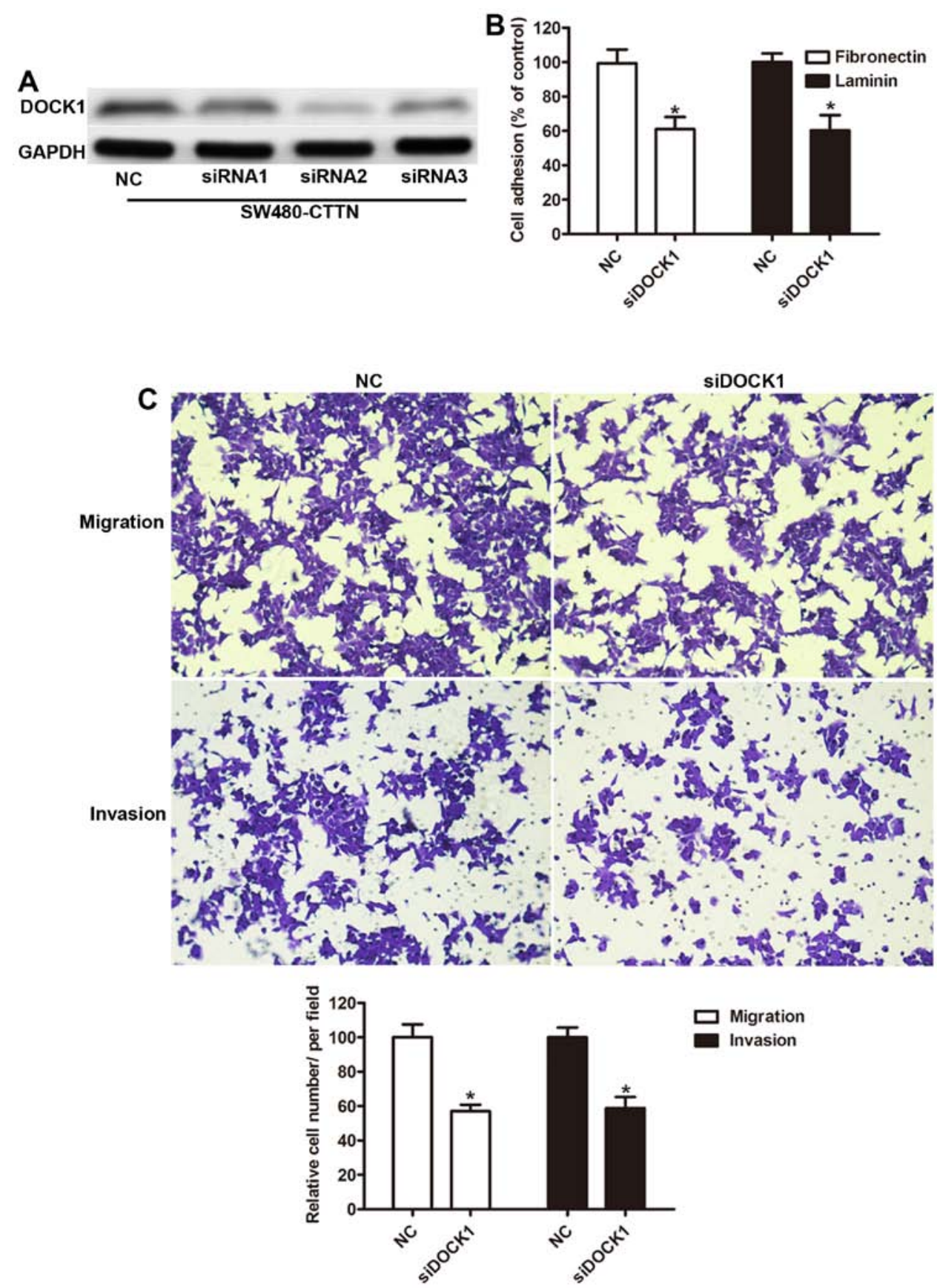

Figure 5. DOCK1 is involved in CTTN-mediated cell mobility. (A) Western blotting was performed to assess the knockdown efficiency in stable overexpressing CTTN SW480 cells transfected with siRNA targeting DOCK1. (B) Cell adhesion assay showing that DOCK1 silencing abolished adhesion capability induced by CTTN. (C) Transwell arrays showing that DOCK1 silencing decreased the mean number of cells penetrating the Transwell membrane and Matrigel induced by CTTN. ${ }^{*} \mathrm{P}<0.05$. 
tumorigenesis and metastasis of numerous malignant tumors including esophageal squamous cell carcinoma, breast, and colon cancer (16,21-23). However, the prognostic significance of CTTN in CRC has not yet been reported. Our results showed that the expression of CTTN was increased in CRC tissues. Pathologic investigation of CRC patient tissues suggested a significant correlation between CTTN expression depth of invasion, lymph node metastasis, and Tumor-Node-Metastasis stage. Kaplan-Meier analysis showed that patients with high CTTN expression had a shorter OS and DFS. In vitro experiments, CTTN silencing inhibited the invasive capability of CRC cells, whereas overexpression of CTTN promote CRC invasion. These data imply that CTTN might be involved in $\mathrm{CRC}$ initiation and progression by acting as an oncogene.

Aberrant expression of CTTN was associated with worse prognosis in esophageal cancer and laryngeal premalignancy $(12,15)$. Our immunohistochemical analysis showed an increase of CTTN protein levels in CRC tumors compared with the adjacent non-tumor tissues, which agreed with a previous study (16). In addition, we found that high CTTN expression had poor prognosis, which further reinforced that CTTN played a significant role in the progress of CRC. In order to understand the connection between CTTN and CRC cell invasion in more detail, it was necessary to identify genes by which DJ-1 regulated invasion. DOCK1, a guanine nucleotide exchange factor, has been reported to promote cell proliferation, motility and survival by activating Rac1 $(18,24)$. DOCK1 also interacted with ELMO1 and Gai2 regulated the actin cytoskeleton enhanced tumor metastasis in breast cancer (25). In the present study, our data suggested that invasion by CTTN CRC cells is dependent of the activation of DOCK1-Rac1, which was confirmed by inhibition of DOCK1 abolishing the effects of CTTN on migration and invasion. However, the expression and roles of DOCK1 require further study in CRC.

In summary, our data indicated that the level of CTTN expression correlates with clinicopathological features and patient survival in CRC and contributed to invasion and metastasis of CRC in vitro. Furthermore, our findings emphasize the potential role of DOCK1 in CTTN-mediated cell migration and invasion. Our findings may shed new light on the prognostic markers for CRC and novel therapeutic targets for CRC invasion intervention.

\section{Acknowledgements}

This study was supported by grants from the Nature Science Foundation of China (no. 81272751).

\section{References}

1. Jemal A, Bray F, Center MM, Ferlay J, Ward E and Forman D: Global cancer statistics. CA Cancer J Clin 61: 69-90, 2011.

2. Liu Z, Zhang Y, Franzin L, Cormier JN, Chan W, Xu H and Du XL: Trends and variations in breast and colorectal cancer incidence from 1995 to 2011: A comparative study between Texas Cancer Registry and National Cancer Institute's Surveillance, Epidemiology and End Results data. Int J Oncol 46: 1819-1826, 2015.

3. Jemal A, Center MM, DeSantis C and Ward EM: Global patterns of cancer incidence and mortality rates and trends. Cancer Epidemiol Biomarkers Prev 19: 1893-1907, 2010.

4. Ramasamy TS, Ayob AZ, Myint HH, Thiagarajah S and Amini F: Targeting colorectal cancer stem cells using curcumin and curcumin analogues: Insights into the mechanism of the therapeutic efficacy. Cancer Cell Int 15: 96, 2015.
5. Kang H, O'Connell JB, Maggard MA, Sack J and Ko CY: A 10 -year outcomes evaluation of mucinous and signet-ring cell carcinoma of the colon and rectum. Dis Colon Rectum 48: 1161-1168, 2005.

6. Cunningham D, Atkin W, Lenz HJ, Lynch HT, Minsky B, Nordlinger B and Starling N: Colorectal cancer. Lancet 375: 1030-1047, 2010.

7. Ni B, Yu X, Guo X, Fan X, Yang Z, Wu P, Yuan Z, Deng Y, Wang J, Chen D, et al: Increased urothelial cancer associated 1 is associated with tumor proliferation and metastasis and predicts poor prognosis in colorectal cancer. Int J Oncol 47: 1329-1338, 2015.

8. Gupta GP and Massagué J: Cancer metastasis: Building a framework. Cell 127: 679-695, 2006.

9. Tsai JH and Yang J: Epithelial-mesenchymal plasticity in carcinoma metastasis. Genes Dev 27: 2192-2206, 2013.

10. Liao MY, Kuo MY, Lu TY, Wang YP and Wu HC: Generation of an anti-EpCAM antibody and epigenetic regulation of EpCAM in colorectal cancer. Int J Oncol 46: 1788-1800, 2015.

11. Weaver AM: Cortactin in tumor invasiveness. Cancer Lett 265: 157-166, 2008.

12. Rodrigo JP, Álvarez-Alija G, Menéndez ST, Mancebo G, Allonca E, García-Carracedo D, Fresno MF, Suárez C and GarcíaPedrero JM: Cortactin and focal adhesion kinase as predictors of cancer risk in patients with laryngeal premalignancy. Cancer Prev Res (Phila) 4: 1333-1341, 2011.

13. Weed SA, Karginov AV, Schafer DA, Weaver AM, Kinley AW, Cooper JA and Parsons JT: Cortactin localization to sites of actin assembly in lamellipodia requires interactions with F-actin and the Arp2/3 complex. J Cell Biol 151: 29-40, 2000.

14. Bryce NS, Clark ES, Leysath JL, Currie JD, Webb DJ and Weaver AM: Cortactin promotes cell motility by enhancing lamellipodial persistence. Curr Biol 15: 1276-1285, 2005.

15. Hill A, McFarlane S, Mulligan K, Gillespie H, Draffin JE, Trimble A, Ouhtit A, Johnston PG, Harkin DP, McCormick D, et al: Cortactin underpins CD44-promoted invasion and adhesion of breast cancer cells to bone marrow endothelial cells. Oncogene 25: 6079-6091, 2006.

16. Hirakawa $H$, Shibata $K$ and Nakayama T: Localization of cortactin is associated with colorectal cancer development. Int $\mathbf{J}$ Oncol 35: 1271-1276, 2009.

17. Chi Y, Huang S, Liu M, Guo L, Shen X and Wu J: Cyclin D3 predicts disease-free survival in breast cancer. Cancer Cell Int 15: 89, 2015.

18. Feng H, Hu B, Liu KW, Li Y, Lu X, Cheng T, Yiin JJ, Lu S, Keezer S, Fenton T, et al: Activation of Racl by Src-dependent phosphorylation of Dock180(Y1811) mediates PDGFR $\alpha$ stimulated glioma tumorigenesis in mice and humans. J Clin Invest 121: 4670-4684, 2011.

19. Li H, Yang L, Fu H, Yan J, Wang Y, Guo H, Hao X, Xu X, Jin $\mathrm{T}$ and Zhang N: Association between Gai2 and ELMO1/ Dock 180 connects chemokine signalling with Rac activation and metastasis. Nat Commun 4: 1706, 2013.

20. Jing F, Kim HJ, Kim CH, Kim YJ, Lee JH and Kim HR: Colon cancer stem cell markers CD44 and CD133 in patients with colorectal cancer and synchronous hepatic metastases. Int J Oncol 46: 1582-1588, 2015.

21. Luo ML, Shen XM, Zhang Y, Wei F, Xu X, Cai Y, Zhang X, Sun YT, Zhan QM, Wu M, et al: Amplification and overexpression of CTTN (EMS1) contribute to the metastasis of esophageal squamous cell carcinoma by promoting cell migration and anoikis resistance. Cancer Res 66: 11690-11699, 2006.

22. Lee MS, Kim S, Kim BG, Won C, Nam SH, Kang S, Kim HJ, Kang M, Ryu J, Song HE, et al: Snaill induced in breast cancer cells in 3D collagen I gel environment suppresses cortactin and impairs effective invadopodia formation. Biochim Biophys Acta 1843: 2037-2054, 2014.

23. Kozyreva VK, McLaughlin SL, Livengood RH, Calkins RA, Kelley LC, Rajulapati A, Ice RJ, Smolkin MB, Weed SA and Pugacheva EN: NEDD9 regulates actin dynamics through cortactin deacetylation in an AURKA/HDAC6-dependent manner. Mol Cancer Res 12: 681-693, 2014.

24. Côté JF and Vuori K: GEF what? Dock180 and related proteins help Rac to polarize cells in new ways. Trends Cell Biol 17: 383-393, 2007.

25. Laurin M, Huber J, Pelletier A, Houalla T, Park M, Fukui Y, Haibe-Kains B, Muller WJ and Côté JF: Rac-specific guanine nucleotide exchange factor DOCK1 is a critical regulator of HER2-mediated breast cancer metastasis. Proc Natl Acad Sci USA 110: 7434-7439, 2013. 